\title{
A new chlorophyll $d$-containing cyanobacterium: evidence for niche adaptation in the genus Acaryochloris
}

\author{
Remus Mohr ${ }^{1,2,3}$, Björn Voß ${ }^{1}$, Martin Schliep ${ }^{2}$, Thorsten Kurz ${ }^{4}$, Iris Maldener ${ }^{5}$, \\ David G Adams ${ }^{6}$, Anthony DW Larkum², Min Chen ${ }^{2}$ and Wolfgang R Hess ${ }^{1}$ \\ ${ }^{1}$ Faculty of Biology, University of Freiburg, Freiburg, Germany; ${ }^{2}$ School of Biological Sciences (A08), \\ University of Sydney, Sydney, New South Wales, Australia; ${ }^{3}$ Spemann Graduate School of Biology and \\ Medicine, University of Freiburg, Freiburg, Germany; ${ }^{4}$ Center for Systems Biology, University of Freiburg, \\ Freiburg, Germany; ${ }^{5}$ Institute of Microbiology and Infection Medicine/Organismic Interactions, University \\ of Tübingen, Tübingen, Germany and ${ }^{6}$ Faculty of Biological Sciences, University of Leeds, Leeds, UK
}

\begin{abstract}
Chlorophyll $d$ is a photosynthetic pigment that, based on chemical analyses, has only recently been recognized to be widespread in oceanic and lacustrine environments. However, the diversity of organisms harbouring this pigment is not known. Until now, the unicellular cyanobacterium Acaryochloris marina is the only characterized organism that uses chlorophyll $d$ as a major photopigment. In this study we describe a new cyanobacterium possessing a high amount of chlorophyll $d$, which was isolated from waters around Heron Island, Great Barrier Reef $\left(23^{\circ} 26^{\prime} 31.2^{\prime \prime}\right.$ $\left.\mathrm{S}, 151^{\circ} 54^{\prime} 50.4^{\prime \prime} \mathrm{E}\right)$. The $16 \mathrm{~S}$ ribosomal RNA is $2 \%$ divergent from the two previously described isolates of $\boldsymbol{A}$. marina, which were isolated from waters around the Palau islands (Pacific Ocean) and the Salton Sea lake (California), suggesting that it belongs to a different clade within the genus Acaryochloris. An overview sequence analysis of its genome based on Illumina technology yielded 871 contigs with an accumulated length of $8371965 \mathrm{nt}$. Their analysis revealed typical features associated with Acaryochloris, such as an extended gene family for chlorophyll-binding proteins. However, compared with A. marina MBIC11017, distinct genetic, morphological and physiological differences were observed. Light saturation is reached at lower light intensities, Chl $d / a$ ratios are less variable with light intensity and the phycobiliprotein phycocyanin is lacking, suggesting that cyanobacteria of the genus Acaryochloris occur in distinct ecotypes. These data characterize Acaryochloris as a niche-adapted cyanobacterium and show that more rigorous attempts are worthwhile to isolate, cultivate and analyse chlorophyll $d$-containing cyanobacteria for understanding the ecophysiology of these organisms.

The ISME Journal (2010) 4, 1456-1469; doi:10.1038/ismej.2010.67; published online 27 May 2010

Subject Category: microbial ecology and functional diversity of natural habitats

Keywords: Acaryochloris; chlorophyll d; coral reef; cyanobacteria; microbial diversity; overview sequencing
\end{abstract}

\section{Introduction}

Chemical sediment analysis has shown only recently that the distribution and contribution of chlorophyll $d(\mathrm{Chl} d)$-producing organisms to marine primary productivity has been seriously underestimated so far (Kashiyama et al., 2008). These analyses suggested that such organisms potentially thrive in most aquatic environments on Earth, offshore in hemipelagic to pelagic marine conditions, in saline as well as freshwater lakes. However, despite this recently recognized ecological

Correspondence: WR Hess, Faculty of Biology, University of Freiburg, Schaenzlestr. 1, Freiburg, 79104, Germany.

E-mail: Wolfgang.Hess@biologie.uni-freiburg.de

Received 6 January 2010; revised 29 March 2010; accepted 18 April 2010; published online 27 May 2010 relevance, there have been few attempts to isolate, cultivate and analyse the organisms involved. The history of Chl $d$ and of the organisms producing it has been enigmatic for several aspects.

Discovered as early as in 1943, Chl $d$ was first attributed to marine macrophytic red alga (Manning and Strain, 1943). More than half a century later, Miyashita et al. (1996) succeeded in isolating Acaryochloris marina (strain MBIC11017), a unicellular cyanobacterium that uses Chl $d$ as its main photopigment. By now, it could be shown that the Chl $d$ found in red algae species originates from colonial Acaryochloris living on the surface of the algae (Miyashita et al., 2003). A second isolate belonging to the $A$. marina clade (strain CCMEE5401) was characterized only in 2005, isolated from a site very different from the first one, the Salton Sea saltwater lake in California (Miller et al., 2005). 
However, comparing the 16S rRNA sequences of both strains, these were found to be surprisingly similar (identity 99.2\%) and to contain a characteristic insertion, most likely from a $\gamma$-proteobacterium, characterizing the small-subunit rRNA gene of Acaryochloris as a proteobacterial-cyanobacterial hybrid (Miller et al., 2005).

Unlike most other photooxygenic organisms, Acaryochloris uses Chl $d$ as a main pigment in the reaction centres and for photosynthetic light harvesting, instead of Chl $a$. Chl $d$ absorbs light in the near-infrared region and is believed so far to be unique to the genus Acaryochloris. Because of the photophysiological properties of Chl $d$, Acaryochloris occupies an ecological niche rich in far-red light (Kühl et al., 2005). Today, Acaryochloris is considered to be the source of Chl $d$-based photosynthesis. It is often found in proximity to other organisms such as red algae or ascidians such as Lissoclinum patella (Murakami et al., 2004; Kühl et al., 2005) and seems to be widespread according to the analysis of partial 16S rRNA sequences from environmental DNA samples (McNamara et al., 2006; de los Rios et al., 2007; Goh et al., 2009). The genome of the A. marina MBIC11017 was recently analysed and was found to be one of the largest cyanobacterial genomes ever studied. It encompasses a total of 8.3 million base pairs that are distributed between one master chromosome of 6503724 base pairs and an additional 9 plasmids (Swingley et al., 2008). This unusual genome organization and the fact that approximately $25 \%$ of its genes reside in the plasmids gave rise to the idea of an increased lateral gene transfer within the family (Swingley et al., 2008). Despite these intriguing features, the Acaryochloris species complex is still poorly described.

Using red light-emitting diode lights during the enrichment phase (Duxbury et al., 2009), we succeeded in isolating a new free-living cyanobacterium that is dominated by Chl $d$. In this study we present a polyphasic approach to describe this new strain, referred to as Acaryochloris sp. HICR111A, which shows morphological, physiological and genomic differences with the $A$. marina isolate. Acaryochloris sp. HICR111A has been isolated from Heron Island in the Capricornia Cays of the Australian Great Barrier Reef. It grows in tight cell aggregates and lacks phycocyanin but not allophycocyanin, which is different from other isolates. The 16S rRNA identity between strain HICR111A, MBIC11017 and CCMEE5401 is only $98 \%$. Moreover, the distribution and arrangement of crucial photosynthetic genes is different and the light saturation of Acaryochloris sp. HICR111A is reached at lower light intensities compared with A. marina.

We conclude that Acaryochloris sp. HICR111A is a new representative of the Acaryochloris clade that seems to be distinct with regard to habitat, morphology and genomic features, underlining that the
Acaryochloris group is still strongly undersampled. Our data emphasize the importance of isolation and cultivation of more isolates of this outstanding family of cyanobacteria. A greater number of isolates and additional genomic data will facilitate understanding a fascinating piece of microbial diversity, the scope and mechanisms of Acaryochloris genomic diversity and the role of Chl $d$-driven photosynthesis in various habitats.

\section{Materials and methods}

Isolation and culture conditions

Samples were isolated on Heron Island, Great

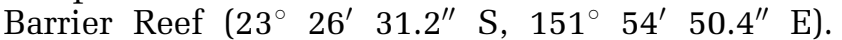
The sample material was a dead coral skeleton that was overgrown with algae and cyanobacteria and was found in shallow water on the southern reef flat of Heron Island. After growing in mixed enrichment cultures in ASN (artificial seawater + BG-11 nutrients), subcultures were grown in near-infrared light-emitting diode light $(700-740 \mathrm{~nm}$, centred at $720 \mathrm{~nm}$ with $20 \mathrm{~nm}$ half width; Roithner Laser Technik, Vienna, Austria) as recently described (Duxbury et al., 2009). The presence of Chl $d$ was monitored spectrophotometrically and by high performance liquid chromatography (HPLC) in 100\% methanol extracts. Those cultures showing relevant amounts of Chl $d$ were further subcultured. All cultures were grown in ASN at $25^{\circ} \mathrm{C}$. The isolated unicyanobacterial strain was grown in both continuous red and low-intensity white light $(20-30 \mu \mathrm{mol}$ photo$\mathrm{ns} \mathrm{m}^{-2} \mathrm{~s}^{-1}$ ). It has been deposited in the Roscoff Culture Collection from where it is publicly available under the accession number RCC1983.

\section{Microscopy}

Light and fluorescence microscopy pictures were taken using a Zeiss Axioskop 40 FL (Carl Zeiss MicroImaging GmbH, Göttingen, Germany) with a HB50 mercury lamp. The fluorescence filter excites at $450-490 \mathrm{~nm}$ and allows long-path emission $(>515 \mathrm{~nm})$.

\section{Light saturation measurements}

Chl $d$ concentrations were determined according to Ritchie (2006). Light saturation curve measurements were performed in triplicates with a red diode pulse amplitude modulation (Heinz Walz GmbH, Effeltrich, Germany) fluorometer with electron transfer rate monitored versus increasing intensities of photosynthetically active radiation. Relative electron transfer rate could be calculated based on the known amounts of Chl $d$ on the measured surface. We applied the correlation of relative electron transfer rate and oxygen evolution as shown for A. marina by Gloag et al. (2007). The obtained data points were fitted using the waiting-in-line model as in Ritchie (2008). 
High performance liquid chromatography

HPLC analysis was performed using a Shimadzu VP series HPLC system with a SCL-10A system controller and a SPD-M10A diode array detector (Shimadzu, Kyoto, Japan). All HPLC data were integrated and analysed using Class-VP 6.14 software (Shimadzu). For all analytical work, a reverse-phase C18 column (Synergi Fusion-RP 80A, $250 \mathrm{~mm} \times 4.6 \mathrm{~mm}, 4 \mu \mathrm{m}$ pore size; Phenomenex, Torrance, CA, USA) was used. Mobile phase was a gradient mixture of acetonitrile (40-0\%), methanol (50-100\%) and $0.1 \mathrm{M} \mathrm{NH}_{4} \mathrm{Ac}(10-0 \%)$ with a flow rate of $1 \mathrm{ml} \mathrm{min}^{-1}$. Column was equilibrated $30 \mathrm{~min}$ before each run with equilibration buffer: $50 \%$ methanol, $40 \%$ acetonitrile and $10 \% \quad 0.1 \mathrm{M} \mathrm{NH}_{4}$ Ac. After each run the column was cleaned with five volumes of $100 \%$ ethyl acetate. All solvents used were HPLC grade (Malinckrodt Baker, Phillipsburg, NJ, USA) and degassed by vacuum filtration and ultrasonication just before use. Calculation of ratio values was based on HPLC chromatogram peak areas. Each peak was evaluated individually in silico at its published absorption maximum wavelength and normalized to its extinction coefficient $\varepsilon$ at this wavelength in methanol $\left(\varepsilon=77.62 \mathrm{~mol}^{-1} \mathrm{~cm}^{-1}\right.$ at $696 \mathrm{~nm}$ for Chl $d ; \varepsilon=68.72 \mathrm{~mol}^{-1} \mathrm{~cm}^{-1}$ at $665 \mathrm{~nm}$ for Chl $a ; \varepsilon=44.6 \mathrm{~mol}^{-1} \mathrm{~cm}^{-1}$ at $667 \mathrm{~nm}$ for phaeophytin $a$; and $\varepsilon=133 \mathrm{~mol}^{-1} \mathrm{~cm}^{-1}$ at $452 \mathrm{~nm}$ for zeaxanthin; Jeffrey and Vesk, 1997; Ritchie, 2006).

\section{Spectroscopic measurements in the absence or} presence of glycerol

The spectrofluorimetric assay of Wyman et al. (1985) was adapted to measure the possible detachment of phycobiliproteins from the photosynthetic membrane. Fluorescence emission spectra were determined using an Aminco-Bowman Series 2 luminescence spectrometer (Thermo Spectronic, Madison, WI, USA) equipped with a red-sensitive photomultiplier. For measurements, $1 \mathrm{ml}$ of thoroughly resuspended cell culture was mixed with $1 \mathrm{ml}$ of glycerol (to a final concentration of $50 \%, \mathrm{v} / \mathrm{v}$ ) or culture medium to yield similar Chl concentrations, transferred to the measuring cuvette and frozen in liquid nitrogen immediately. Fluorescence was excited at 470, 495 and $550 \mathrm{~nm}$ in the presence or absence of glycerol.

\section{DNA isolation and PCR}

A $50 \mathrm{ml}$ cell culture was harvested by centrifugation and washed twice with SET buffer $(40 \% \mathrm{w} / \mathrm{v}$ sucrose, $50 \mathrm{~mm}$ Tris-HCl pH 8.0 and $1 \mathrm{mM}$ EDTA). The pellet was frozen and thawed, followed by a proteinase $\mathrm{K}$ digestion at $50^{\circ} \mathrm{C}$ overnight followed by phenol-chloroform phase separation (Finsinger et al., 2008). Taq polymerase (Promega, Madison, WI, USA) and primers 16SCYfw (5'-GGCTCAGGAT GAACGCTGGCGG-3') and 16SCYrv (5'-ACCTTGT TACGACTTCACCCCAGTC-3') were used to amplify the 16S rRNA gene in 35 cycles of denaturation for $30 \mathrm{~s}$ at $93{ }^{\circ} \mathrm{C}$, annealing at $60^{\circ} \mathrm{C}$ for $30 \mathrm{~s}$ and elongation for $60 \mathrm{~s}$ at $72{ }^{\circ} \mathrm{C}$. Amplified 16S rRNA gene fragments were cloned into the pGEM-T vector System 1 (Promega), transformed into Escherichia coli and sequenced.

Field emission gun scanning electron microscope Samples were fixed with $2.5 \%$ (vol/vol) glutaraldehyde in $0.1 \mathrm{M}$ phosphate buffer $(\mathrm{pH} 7.2)$ for $2.5 \mathrm{~h}$. Fixed cells were washed twice, for 30 min each time, in $0.1 \mathrm{M}$ phosphate buffer, and postfixed with $1.0 \%$ $(\mathrm{w} / \mathrm{v})$ osmium tetroxide in $0.1 \mathrm{M}$ phosphate buffer. The cells were then dehydrated by $30-\mathrm{min}$ washes in a graded acetone series of $20 \%(\mathrm{v} / \mathrm{v}), 40 \%, 60 \%$, and $80 \%$ and a final two washes in $100 \%$. Samples were critical-point dried, mounted on aluminium pin stubs, and coated with a 5-nm layer of platinum and palladium using an Agar Scientific high-resolution sputter coater fitted with an Agar Scientific (Agar Scientific Ltd., Stansted, UK) thickness monitor. Samples were examined with an LEO (LEO Elektronenmikroskopie $\mathrm{GmbH}$, Oberkochen, Germany) 1530 series field emission gun scanning electron microscope instrument operating at $3 \mathrm{kV}$.

\section{Transmission electron microscopy}

Samples for electron microscopy were prepared as in Fiedler et al. (1998) with slight modifications: cell cultures were harvested and the cells were fixed overnight with $2 \%$ glutaraldehyde and incubated in $2 \% \mathrm{KMnO}_{4}$ at $4 \mathrm{C}$ for $16 \mathrm{~h}$. The cells were embedded in $1 \%$ Seakem agarose, which was cut in pieces of $1 \mathrm{~mm}^{2}$. The samples were dehydrated by a $20-\mathrm{min}$ graded ethanol series of $70 \%(\mathrm{v} / \mathrm{v}), 80 \%, 90 \%, 95 \%$ and a final three washes in $100 \%$ ethanol, followed by infiltration with ethanol/Epon (1:2) for $30 \mathrm{~min}$, and 90-min incubation in ethanol/Epon (1:3). Finally, the agarose cubes were embedded in pure Epon by incubation at $40^{\circ} \mathrm{C}$ for $24 \mathrm{~h}$ and at $60{ }^{\circ} \mathrm{C}$ for $48 \mathrm{~h}$. Ultrathin sections $(70-80 \mathrm{~nm})$ were mounted on pioloform-coated copper grids and poststained with $2 \%$ uranyl acetate in ethanol and lead citrate (Reynolds, 1963). Electronmicrographs were imaged using a Philips Tecnai electron microscope (FEI EUROPE, Eindhoven, The Netherlands) at $80 \mathrm{kV}$.

\section{Genome analysis}

The DNA was extracted as mentioned above. As an additional step the DNA was treated with $10 \mu \mathrm{g} \mathrm{ml}^{-1}$ RNase A at room temperature for $30 \mathrm{~min}$ followed by another phenol-chloroform phase separation to remove the RNase. The DNA was precipitated with $70 \%$ ethanol with sodium acetate and checked for purity on a $1 \%$ agarose gel. For overview sequencing, a single paired-end (200 bp distance) run on an Illumina (San Diego, CA, USA) (Solexa) sequencer was performed, yielding $\sim 85$ million reads with a length of $76 \mathrm{nt}$. The Velvet collection of 
algorithms (Zerbino and Birney, 2008) was used for the de novo assembly of obtained sequences using de Bruijn graphs. The initial de novo assembly (parameters: kmerlength $=31$, exp_cov $=$ auto and cov_cutoff $=$ auto) resulted in two distinct populations of contigs, characterized by their different GC content, centred either between $58 \%$ and $66 \%$ GC or between $40 \%$ and $48 \%$ GC (Figure 1). Refining the assembly parameters (kmerlength $=61$, exp_cov $=350$ and cov-cutoff $=10$ ) gave a significantly better result (in terms of contig lengths) for the low GC population, while excluding the population of high GC reads from the assembly. A separate assembly of all unused reads, again, gave two contig populations, one with low and one with high GC (Figure 1). Thus, there seems to be more than one origin of contaminating DNA, and preliminary analyses showed that these bacteria are affiliated to the $\alpha$-proteobacteria. From now on we focused on the refined assembly that produced 871 contigs, ranging in length from 121 to $241276 \mathrm{nt}$. The total size of the assembly was $8371965 \mathrm{nt}$, and the N50 value was $40719 \mathrm{nt}$. The N50 value indicates the length of the contig, in which half of the total length is reached. As the size of the assembly is very similar to the genome size of A. marina, most genomic information can be expected to be found within this data set. After gene modelling and automatic annotation using RAST (Rapid Annotation using Subsystem Technology; Aziz et al., 2008) we found genes with high similarity to Acaryochloris genes.

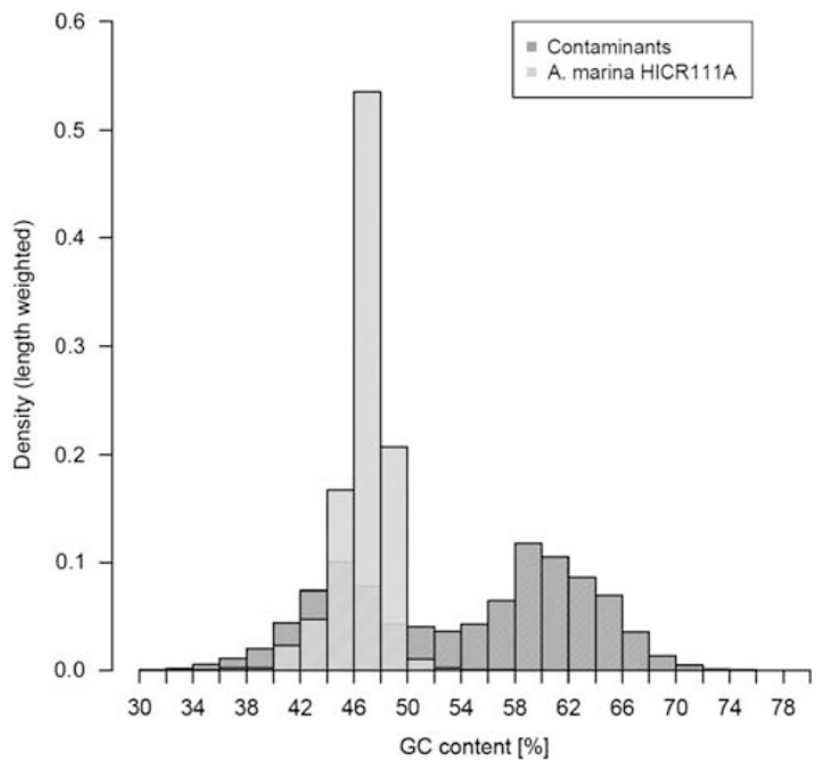

Figure 1 Comparison of the final $A$. marina HICR111A sequence assembly (red) and the assembled contaminant sequences (green) based on GC content. To ensure comparability, the densities have been length-weighted. Although the A. marina contigs are centred around a GC of $47 \%$, the contaminant contigs are distributed between $32 \%$ and $76 \%$ with peaks around $45 \%$ and $59 \%$, respectively (The color reproduction of this figure is available on the html full text version of the manuscript).

\section{Results and discussion}

\section{Morphology}

Unlike A. marina MBIC11017, Acaryochloris sp. HICR111A was not isolated from a cell suspension squeezed out from the colonial ascidian L. patella (Miyashita et al., 1996) or its vicinity (Kühl et al., 2005), but was scraped off a dead coral skeleton overgrown with other algae and cyanobacteria. Applying defined near far-red light conditions to mixed algal cultures enabled us to obtain a unicyanobacterial culture of a Chl $d$-dominated prokaryote. The novel isolate is related to A. marina MBIC11017, yet morphological differences were observed. The culture consistently appears light green, whereas $A$. marina cultures are bluegreen under moderate and low light conditions (Figure 2a). The novel strain grows in aggregates, (Figures $2 \mathrm{~b}-\mathrm{d}$ ), whereas cells of $A$. marina are dispersed as single cells in the medium (Figures 2e-g). Figures $2 \mathrm{~d}$ and g show field emission gun scanning electron microscopy pictures of Acaryochloris sp. HICR111A and $A$. marina, respectively, suggesting that the cell surface of both strains is alike with regard to fibril size and structure. The individual cells are rod shaped and between 1 and $2 \mu \mathrm{m}$ long with a diameter of $0.75-1 \mu \mathrm{m}$, which is somewhat smaller than the $2-3 \mu \mathrm{m}$ in length and the diameter of $1.5-2.0 \mu \mathrm{m}$ reported for $A$. marina (Miyashita et al., 1996) and for other isolates of the complex (Miller et al., 2005; Akimoto et al., 2006). The electron micrographs also show that Acaryochloris sp. HICR111A cells are surrounded by an intercellular matrix that helps the cells to stay attached to each other, which we did not observe for $A$. marina. We suppose that growing in aggregates facilitates attaching to surfaces and settling in near far-red light niches. To a certain extent, this feature can also be observed for the MBIC11017 isolate, but only when they reach stationary phase without shaking. Acaryochloris sp. HICR111A cultures are unicyanobacterial but not axenic. Therefore, the observed intercellular matrix might in part be because of the presence of other bacteria, trying to form a consortium with the phototrophic Acaryochloris.

\section{Pigmentation and photosynthetic parameters}

Figure 3 shows in vivo spectra of Acaryochloris sp. HICR111A and $A$. marina. Both look very similar to each other, showing the typical pattern for a Chl $d$-dominated organism. Compared with Chl $a$ cyanobacteria, the $\mathrm{Q}_{\mathrm{y}}$ band is shifted to the far red with a maximum at $710 \mathrm{~nm}$ for MBIC11017 and $707 \mathrm{~nm}$ for the novel strain. The Soret band is shifted towards the blue-green at $460 \mathrm{~nm}$. Carotenoids absorb at a maximum of $500 \mathrm{~nm}$. Measuring in vivo spectra for Acaryochloris sp. HICR111A is particularly difficult because of scattering and sinking of the cell aggregates, which might have contributed to the slightly broadened peak of the $\mathrm{Q}_{\mathrm{y}}$ band. 


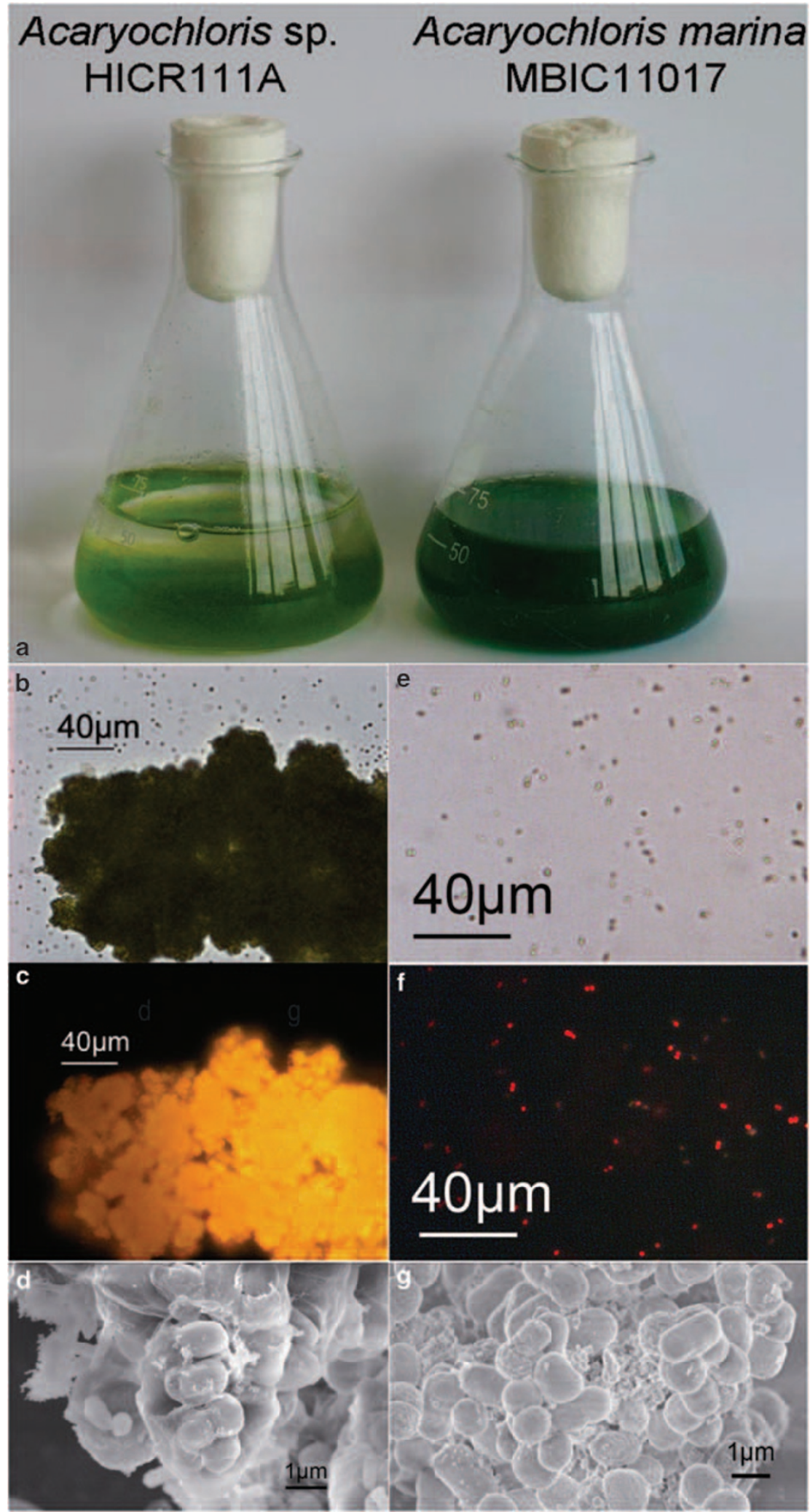

Figure 2 (a) Cultures of Acaryochloris sp. HICR111A appear yellow-green (left flask), and those of $A$. marina MBIC11017 blue-green (right flask). (b) Light microscopy, (c) fluorescence microscopy and (d) field emission gun scanning electron microscopy (FEGSEM) of aggregated Acaryochloris sp. HICR111A. (e) Light microscopy, (f) fluorescence microscopy and (g) FEGSEM of non-aggregated A. marina MBIC11017. Both cultures were grown under medium white light at $25^{\circ} \mathrm{C}$. 


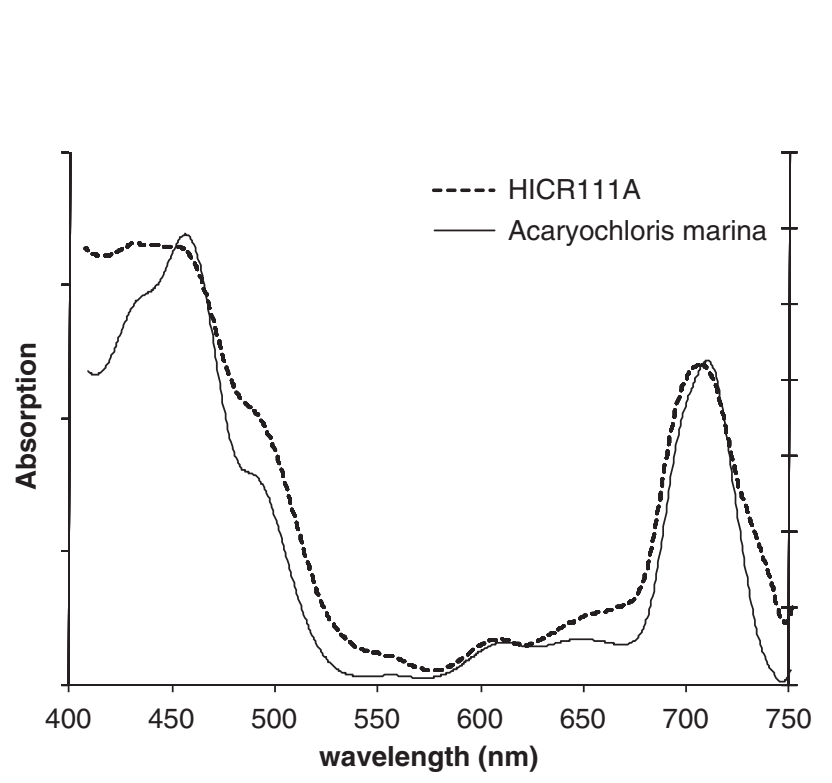

Figure 3 In vivo absorption spectra of Acaryochloris sp. HICR111A and $A$. marina MBIC11017 show the typical features of Chl $d$-dominated organisms. The $\mathrm{Q}_{\mathrm{y}}$ maxima of Chl $d$ were detected at $710 \mathrm{~nm}$ for A. marina MBIC11017 and at $707 \mathrm{~nm}$ for the novel strain.

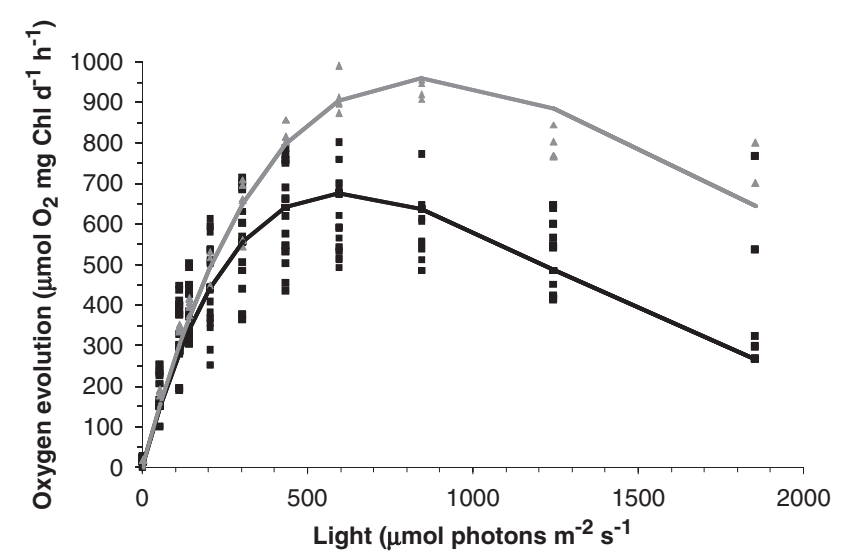

Figure 4 Light saturation curve of Acaryochloris sp. HICR111A (black line) and A. marina MBIC11017 (grey line). The graphs were fitted using the waiting-in-line model (Gloag et al., 2007), and the oxygen evolution was calculated based on the relative electron transfer rate (ETR) (Gloag et al., 2007).

The phycobiliproteins, phycocyanin and allophycocyanin, were detected previously in A. marina (Marquardt et al., 1997; Hu et al., 1999), in which they are associated with the photosynthetic membrane in an unusual way (Chen et al., 2009). However, in this study both strains showed very low absorption in the area in which one would typically expect phycobiliproteins to absorb $(615 \mathrm{~nm}$ for phycocyanin and $650 \mathrm{~nm}$ for allophycocyanin). The low signals observed in this study in the in vivo spectra may partially belong to vibrational bands or constitute derivative bands of chlorophylls. There is neither spectroscopic nor genetic evidence for the presence of phycoerythrin in either strain.

Light saturation curves in Figure 4 show that Acaryochloris sp. HICR111A reaches light saturation at approximately $600 \mu \mathrm{mol}$ photons $\mathrm{m}^{-2} \mathrm{~s}^{-1}$, whereas the MBIC11017 strain becomes saturated only at an illumination of $850 \mu \mathrm{mol}$ photons $\mathrm{m}^{-2} \mathrm{~s}^{-1}$. Moreover, both strains differ in the maximum gross photosynthesis rate. Therefore, Acaryochloris sp. HICR111A cannot use light of higher intensities as efficiently as $A$. marina. Furthermore, in the latter, distinct differences in the pigmentation occurred under different light conditions, whereas Acaryochloris sp. HICR111A showed only minor changes (Figure 5). The Chl $a / \mathrm{Chl} d$ ratio in A. marina MBIC11017 increased significantly with raised light intensity, from $<2 \%$ under low light to approximately 6\% under high light. In Acaryochloris sp. HICR111A, the $\mathrm{Chl} a / \mathrm{Chl} d$ ratio changed only from $\sim 2 \%$ to $2.8 \%$ under the same conditions.

A. marina MBIC11017 and Acaryochloris sp. HICR111A are distinct with regard to the presence of phycobiliproteins

Figure 6 compares $77 \mathrm{~K}$ fluorescence emission spectra of both strains. A. marina shows emission maxima at 730 and $758 \mathrm{~nm}$ after Chl $d$ excitation at $470 \mathrm{~nm}$ (Figure 6a). In contrast, Acaryochloris sp. HICR111A shows a single maximum at $750 \mathrm{~nm}$ (Figure 6b). Moreover, the ratio of the peaks changed in the MBIC11017 strain when phycocyanin was specifically excited at $550 \mathrm{~nm}$. The emission at $758 \mathrm{~nm}$ decreased, whereas signals at 647 and $669 \mathrm{~nm}$ increased compared with the main peak at $730 \mathrm{~nm}$ used for normalization. The peak pattern of the novel strain did not change, suggesting the absence of phycocyanin.

The relatively low amounts may render the direct spectroscopic detection of phycobiliproteins too insensitive. Therefore, we adapted the assay of Wyman et al. (1985) to show the detachment of phycobiliproteins from the photosynthetic membrane by strongly enhanced fluorescence peaks in the presence of glycerol. When fluorescence was excited at $550 \mathrm{~nm}$ (absorbed by phycocyanin), a dramatic increase of phycobiliprotein autofluorescence at $647 \mathrm{~nm}$ was observed in MBIC11017 (Figure 6c) but not in HICR111A (Figure 6d). This observation can be explained assuming glycerolinduced detachment of originally coupled phycobiliprotein complexes from the photosynthetic apparatus, as was shown previously for the phycobiliproteins of Synechococcus (Wyman et al., 1985) and Prochlorococcus (Lokstein et al., 1999; Steglich et al., 2003). Hence, phycocyanin excitation-no longer quenched by energy transfer-is re-emitted as fluorescence in case of the MBIC11017 strain. As the addition of glycerol to Acaryochloris sp. HICR111A did not cause any change in the $77 \mathrm{~K}$ spectra, these results suggest the absence of physiologically relevant amounts of phycobiliproteins in this strain. However, at the ultrastructural level transmission electron microscopy images indicated both strains to be very similar, with condensed thylakoids located close to the cell wall (Figure 7). 


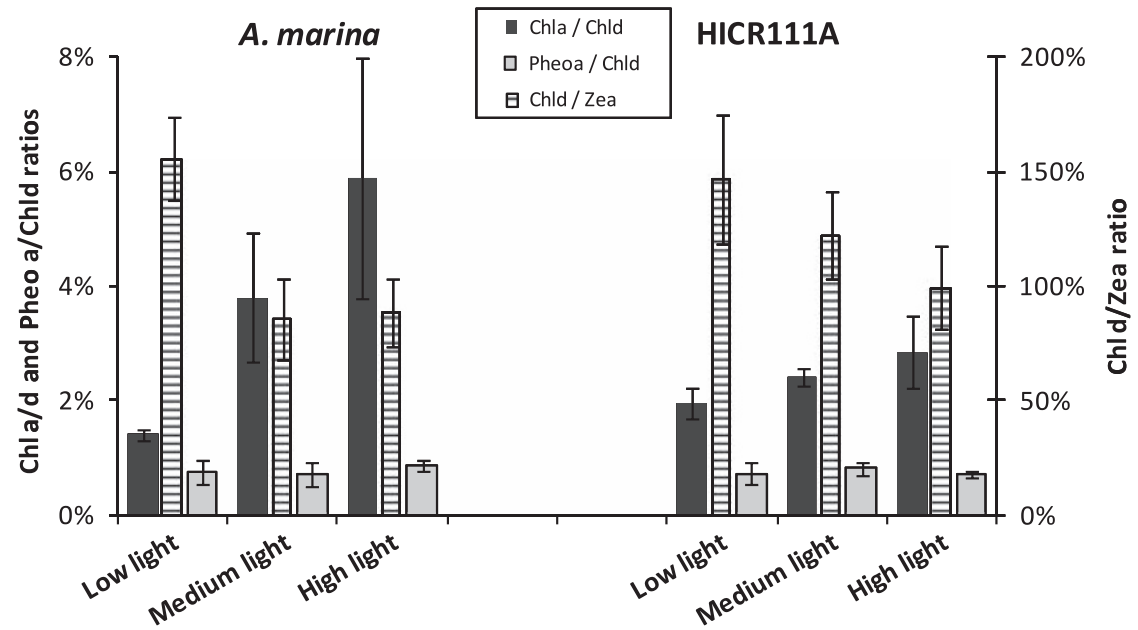

Figure 5 Pigment ratios from A. marina cells (left side) compared with Acaryochloris sp. HICR111A cells (right side) grown under white light of low $\left(5-10 \mu \mathrm{mol}\right.$ photons $\left.\mathrm{m}^{-2} \mathrm{~s}^{-1}\right)$, medium $\left(25-30 \mu \mathrm{mol}\right.$ photons $\left.\mathrm{m}^{-2} \mathrm{~s}^{-1}\right)$ and high $\left(75-100 \mu \mathrm{mol} \mathrm{photons}^{-2} \mathrm{~s}^{-1}\right)$ intensity. Left $y$ axis describes Chl $a / d$ (dark grey bars) and Pheo $a / \mathrm{Chl} d$ (light grey bars) ratios, and right $y$ axis describes the Chl $d / Z$ ea (striped bars) ratio. The data shown are the average of three (A. marina) and two (Acaryochloris sp. HICR111A) experiments with standard errors. Pigment amounts were measured after separation by HPLC.
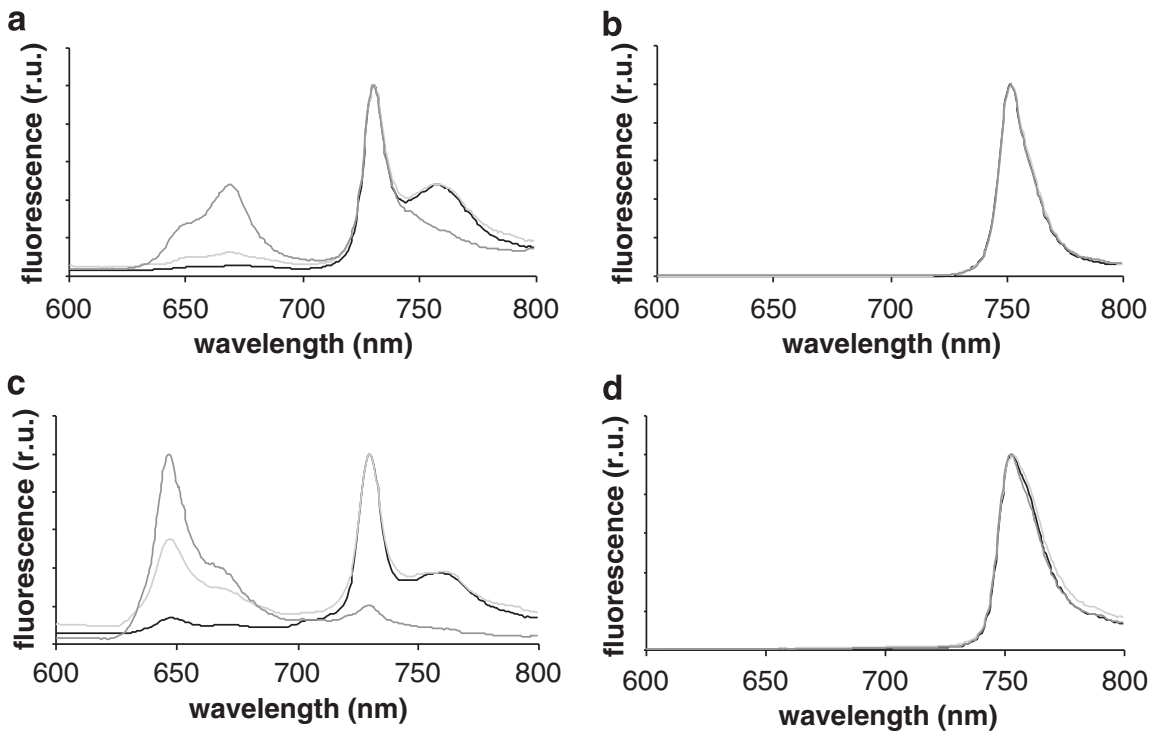

Figure 6 The $77 \mathrm{~K}$ fluorescence emission spectra of $A$. marina (a, c) and Acaryochloris sp. HICR111A (b, d) cells after excitation at $470 \mathrm{~nm}$ (black), $495 \mathrm{~nm}$ (light grey) and $550 \mathrm{~nm}$ (grey). Cells were grown under medium light conditions $\left(25-30 \mu \mathrm{mol} \mathrm{photons} \mathrm{s}^{-1} \mathrm{~m}^{-2}\right)$. (c, d) The effect of glycerol according to Wyman et al. (1985) for the respective strains (relative units (r.u.)) is shown.

\section{Phylogeny}

Figure 8 shows the phylogenetic relationship of Acaryochloris sp. HICR111A within the cyanobacterial kingdom based on a $16 \mathrm{~S}$ rRNA sequence comparison. All three sequences from the genus Acaryochloris group together within the unicellular cyanobacteria group, with Cyanothece PCC7425 being their closest relative. At the 16S rRNA level, Acaryochloris sp. HICR111A shows 98.00\% sequence identity with $A$. marina MBIC11017 and 98.69\% identity with Acaryochloris sp. CMEE5410. Interestingly, Acaryochloris sp. HICR111A forms a separate clade from isolates MBIC11017 and CCMEE5410, which are the two strains of Acaryochloris that have or are having their genomes sequenced (Swingley et al., 2008). With regard to these two strains, Acaryochloris sp. HICR111A represents a more deeply branching isolate. Considering the phylogenetic distance we speculate that diversity of Acaryochloris is high. It seems comparable to the distance between distinct Prochlorococcus and Synechococcus strains that belong to clearly distinct ecotypes, here located in the lower part of the tree. In these picocyanobacteria, a $16 \mathrm{~S}$ rRNA divergence of $2 \%$ is characteristic of a very different ecophysiology and of genomes that differ in the presence of several hundred genes from each other, both in Synechococcus (Dufresne et al., 2008; 

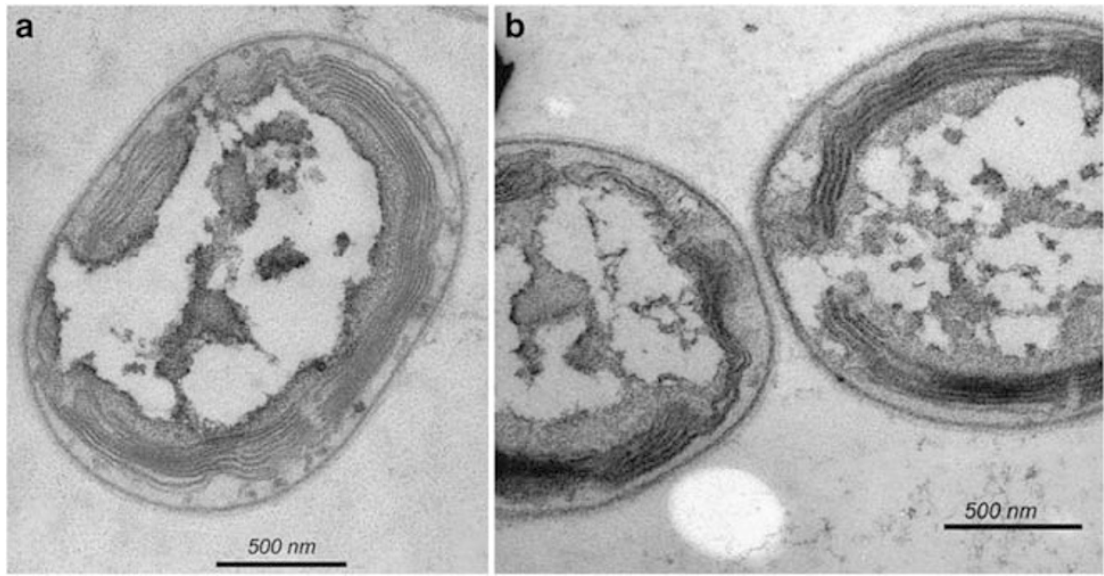

Figure 7 Transmission electron microscopy images of A. marina (a) and Acaryochloris sp. HICR111A (b).

Scanlan et al., 2009) and in Prochlorococcus (Rocap et al., 2003; Kettler et al., 2007). For Acaryochloris, much less data are available but similar differences might be assumed.

Complete 16S rRNA sequences of $>1300 \mathrm{bp}$ are available for very few strains only, mainly because of the lack of adequate isolates. To take environmental and additional sequences into account that might belong to the Acaryochloris clade, we constructed a separate phylogenetic tree based on an alignment of much shorter sequences (Figure 9). Despite not being sufficiently long for a proper phylogenetic analysis, we get a glimpse of the diversity within the Acaryochloris group. All other Acaryochloris strains in culture, such as MBIC11017, Awaji-1 and CCMEE5410, are in one part of the tree, whereas the novel strain HICR111A is the only cultivated representative in another part (Figure 9). Here, Acaryochloris sp. HICR111A forms a shallowly branching clade together with the 'uc clone 11A2 9' sequence. The latter, in fact, originates from the same pre-culture that led to the isolation of Acaryochloris sp. HICR111A and thus was isolated from the very same location, supporting the idea that the new isolate is a representative of a genetically distinct clade.

Analysing more intensely studied cyanobacteria, such as Synechococcus and Prochlorococcus, we suggest that the diversity within the Acaryochloris group might be similar to other picocyanobacteria, which is in line with observations of global distribution of Chl $d$ and of Acaryochloris itself (McNamara et al., 2006; de los Rios et al., 2007; Kashiyama et al., 2008; Goh et al., 2009).

Genomic data support the absence of phycocyanin genes and show features of photosynthetic genes typical for Acaryochloris

To characterize Acaryochloris sp. HICR111A in more detail, an overview sequencing analysis was performed using an Illumina sequencer. The obtained $\sim 85$ million reads of length $76 \mathrm{nt}$ would correspond to a theoretical $375 \times$ genome coverage if a genome size similar to $A$. marina (8 $361608 \mathrm{nt}$ ) is assumed. However, despite attempts over several years we did not succeed in obtaining an axenic culture of the novel strain. Therefore, the genomic data were also expected to contain parts of contaminating sequences. Indeed, during the assembly, two major populations of contigs emerged, characterized by their different GC content, centred either between $58 \%$ and $66 \%$ GC or between $40 \%$ and $48 \%$ GC (Figure 1). Preliminary analyses showed that the reads from the non-Acaryochloris-like bacteria are affiliated to the $\alpha$-proteobacteria, one related to Rhodospirillum spp. and another to the marine Parvularcula bermudensis (Cho and Giovannoni, 2003). Finally, we obtained 871 contigs, with a total size of the assembly of $8371965 \mathrm{nt}$, which is very similar to the genome size of $A$. marina MBIC11017. After gene modelling and automatic annotation, we found genes with high similarity to Acaryochloris genes. Among these genes is the $16 \mathrm{~S}$ rRNA gene of Acaryochloris sp. HICR111A (100\% identity), as well as the widely conserved photosynthetic genes $p s b A$ (for the D1 core subunit of photosystem II) and psbC (encoding the CP43 protein of photosystem II). Thus, a vast majority of genes are found in fragments of substantial length and a more refined analysis seemed promising. For all HICR111A genes mentioned below, Genbank accession numbers are given in Table 1; a full description of this data set is to be published elsewhere.

Two copies of $p s b A$ were found in Acaryochloris sp. HICR111A. A. marina contains three copies of psbA (Swingley et al., 2008). From these, two share $100 \%$ amino acid identity (AM1_2166 and AM1_2889), whereas the third (AM1_0448) codes for a divergent D1 protein and shares only $61 \%$ amino acid identity with the first two (Swingley et al., 2008). Phylogenetic analysis of the two HICR111A D1 proteins showed that both copies 


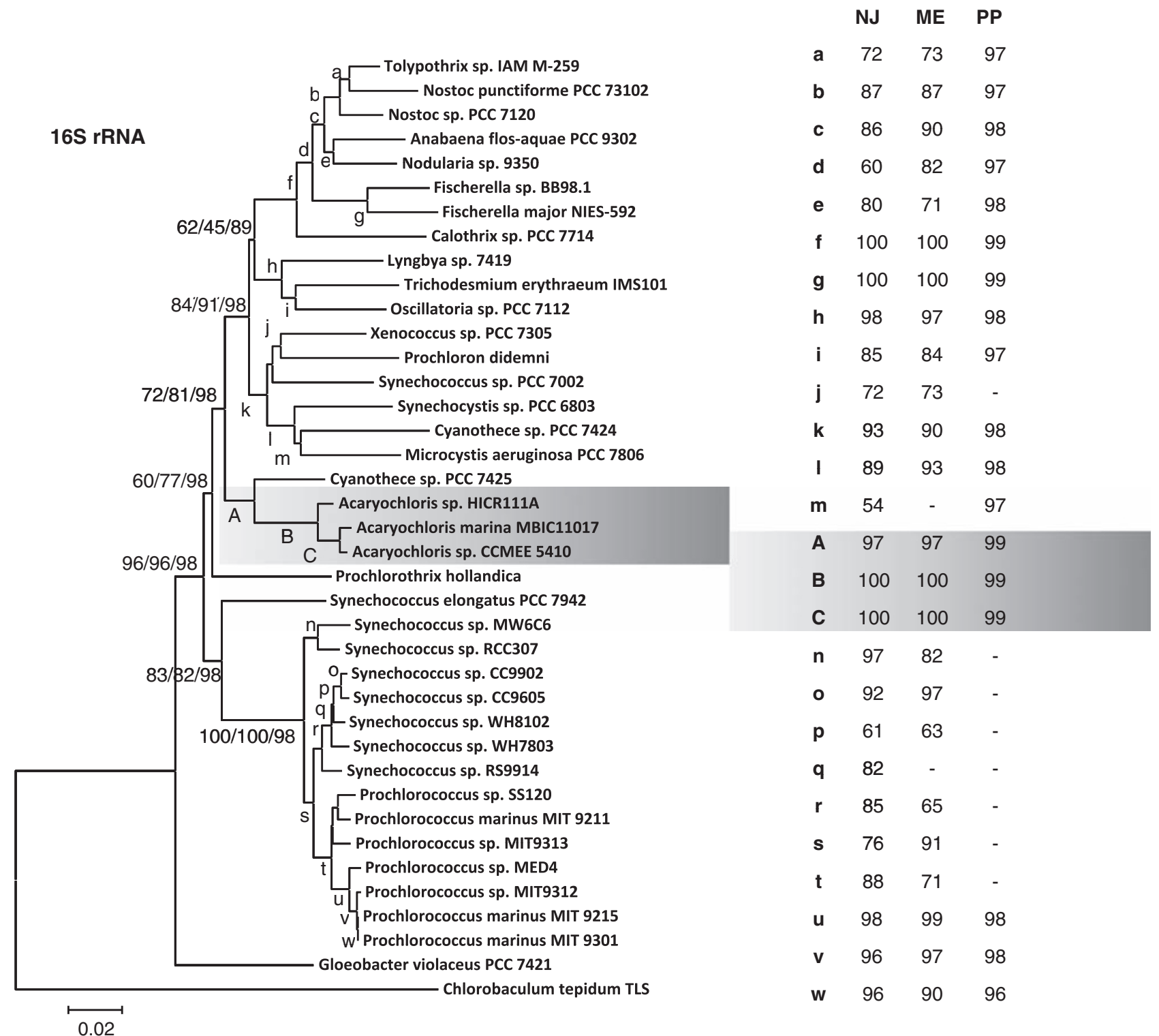

Figure 8 Phylogenetic tree (neighbour joining (NJ)) based on 16S rRNA sequence comparison (1363 bp alignment length; all alignments available upon request) showing the relationship of Acaryochloris HICR111A with other members of the species complex and the position of Acaryochloris within the cyanobacterial kingdom. The comparison contains 39 cyanobacterial taxa, and the green sulphur bacterium Chlorobaculum tepidum as out group. Minimal evolution (ME) and NJ support values with Jukes-Cantor distances, and 10000 bootstrap replicates were calculated using molecular evolutionary genetics analysis (MEGA) software version 4.0 (MEGA 4; Tamura et al., 2007). Bayesian posterior probability (PP) values were calculated using MrBayes 3.1.2. (Huelsenbeck and Ronquist, 2001; Ronquist and Huelsenbeck, 2003). NJ, ME and PP support values are shown in the table next to the tree indicating strong support for most nodes.

group closely with their respective $A$. marina MBIC11017 homologues (Figure 10). One Acaryochloris D1 protein is closely related to its orthologues from Prochlorococcus, Synechocystis and plant plastids; however, the other is not. The presence of two very different D1 forms thus seems as a distinct feature of Acaryochloris. However, the divergent form is closely related to a similarly divergent D1 protein in Anabaena variabilis, two Synechococcus and several Cyanothece strains, all nitrogen-fixing cyanobacteria (Figure 10).
A. marina possesses a set of 12 genes for chlorophyll-binding proteins (CBPs), with 11 in the chromosome and 1 in plasmid pREB3. The major light-harvesting proteins in Acaryochloris, which bind primarily Chl $d$ and a small amount of Chl $a$, belong to this class (Chen et al., 2002). These proteins are homologous to the Pcb-type light-harvesting proteins with six-membranespanning helices as originally defined by LaRoche et al. (1996) for the prochlorophytes. In Acaryochloris, two Pcb types exist (Chen et al., 2005): PcbA 


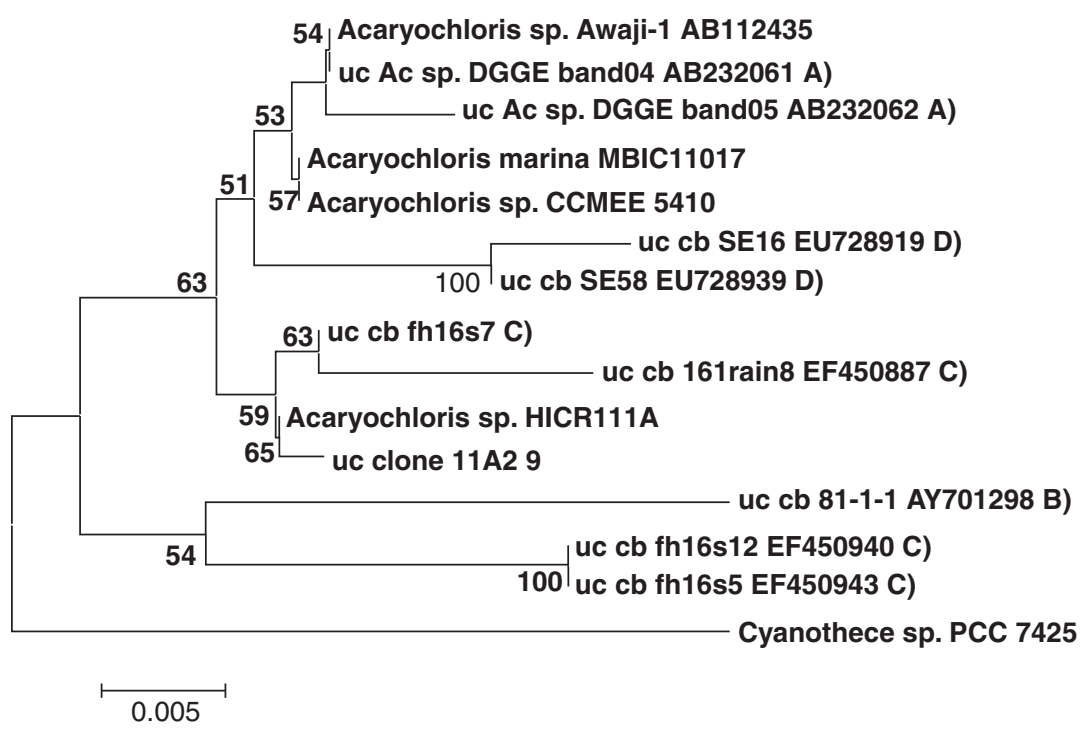

Figure 9 Phylogenetic tree based on 376 bp of the 16S rRNA gene (uc cb, uncultured cyanobacterium; uc Ac, uncultured Acaryochloris). Capital letters indicate the sample origin; A, red algae, Japan; B, Pseudoaxinella flava (sponge)-associated, Bahamas; C, Lyngbyaassociated (Fern Hammick Spring, Florida); and D, Atacama Desert, Bolivia. The evolutionary history was inferred by neighbour joining (NJ; Saitou and Nei, 1987). The percentage of replicate trees in which the associated taxa clustered together in the bootstrap test (1000 replicates) is shown next to the branches.

Table 1 Genbank accession numbers for all mentioned Acaryochloris marina sp. HICR111A genes

\begin{tabular}{ll}
\hline Figure/ID & Definition \\
\hline $\begin{array}{l}\text { Figures } 8 \text { and 9 } \\
\text { Acaryochloris sp. HICR111A }\end{array}$ & $\begin{array}{l}\text { Acaryochloris sp. HICR111A 16S rRNA gene } \\
\text { Uncultured Acaryochloris sp. 16S rRNA gene, clone HICR111A2_9 }\end{array}$ \\
uc clone 11A2_9 & \\
Figure 10 psbA & \\
Acaryochloris sp. HICR111A & psbA1 gene and D1 protein sequence \\
Acaryochloris sp. HICR111Ab & psbA2 gene and D1 protein sequence \\
Figure 11 psbC & \\
PsbC_HICR111A & \\
IsiA_HICR111A & Acaryochloris sp. HICR111A PsbC \\
CBP_h1_HICR111A & Acaryochloris sp. HICR111A IsiA \\
CBP_h2_HICR111A & Acaryochloris sp. HICR111A CBP_h1 \\
CBP_h3_HICR111A & Acaryochloris sp. HICR111A CBP_h2 \\
CBP_h4_HICR111A & Acaryochloris sp. HICR111A CBP_h3 \\
CBP_h5_HICR111A & Acaryochloris sp. HICR111A CBP_h4 \\
CBP_h6_HICR111A & Acaryochloris sp. HICR111A CBP_h5 \\
CBP_h7_HICR111A & Acaryochloris sp. HICR111A CBP_h6 \\
CBP_h8_HICR111A & Acaryochloris sp. HICR111A CBP_h7 \\
Figure 12 Apc & Acaryochloris sp. HICR111A CBP_h8 \\
AH ApcB & \\
AH ApcA1 & \\
AH ApcA2 & apcB gene and protein sequence \\
AH ApcA3 & apcA gene and protein sequence \\
AH ApcA4 & apcA2 gene and protein sequence \\
& apcA3 gene and protein sequence \\
\hline
\end{tabular}

(renamed to CBPII), which are predominantly associated with the photosystem II reaction centre core to form a giant supercomplex (Chen et al., 2008) and PcbC (renamed to CBPI) associated with PSI. The other members of this superfamily are the $p s b C$ gene coding for the CP43 protein of photosystem II and the gene isiA for the iron stress-induced protein IsiA (CBPIII).

The novel strain possesses the genes $p s b C$ and isiA and eight $c b p$ homologues belonging to this superfamily. For most CBPs, exactly one matching homologue was found (Figure 11), which indicates 


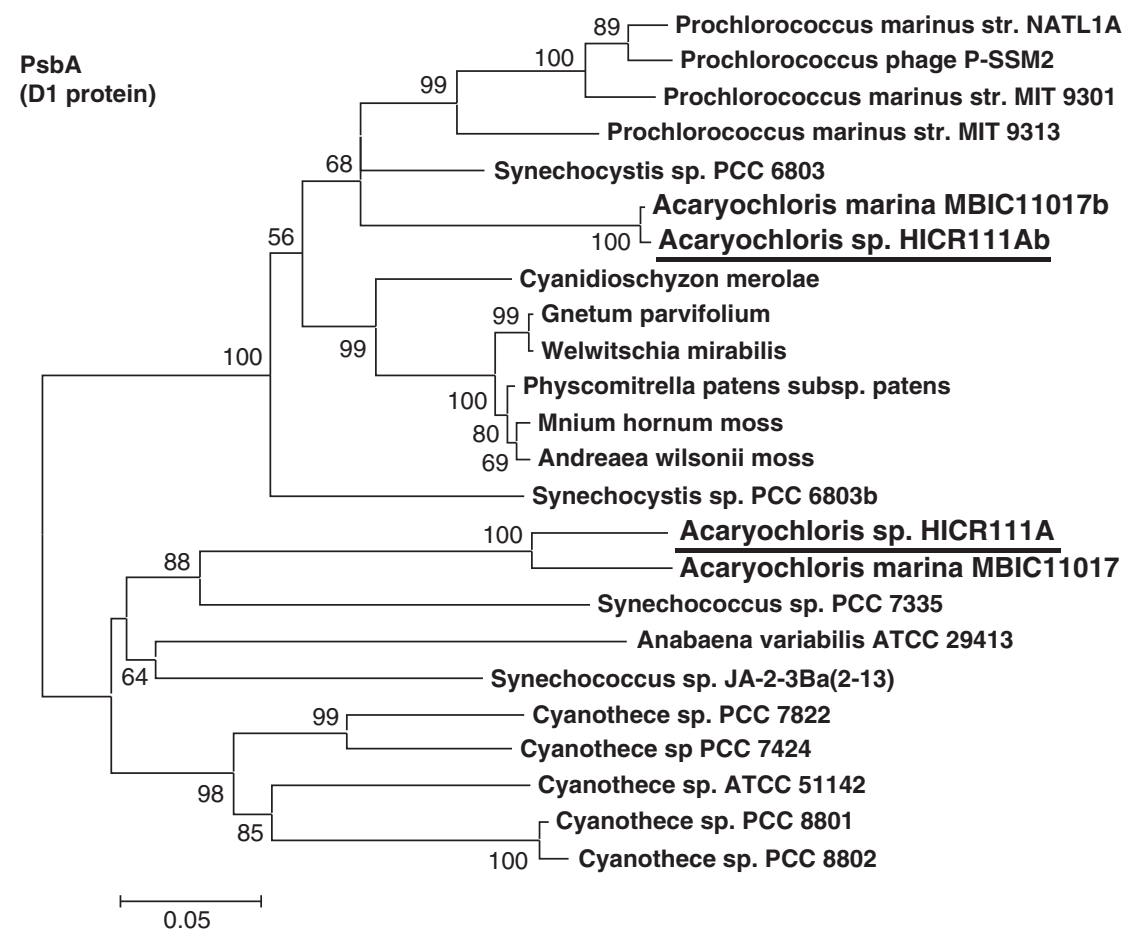

Figure 10 Phylogenetic tree (neighbour joining (NJ)) for the amino acid sequences of the photosynthetic core protein D1 encoded by psbA, calculated using MEGA 4 (Tamura et al., 2007). The percentage of replicate trees in which the associated taxa clustered together in the bootstrap test (1000 replicates) is shown next to the branches. Bootstrap values of $\geqslant 50$ indicate support.

similar strategies in all these strains in constituting the photosynthetic machinery. The missing CBP homologues are CBPIIIb, which belongs to the IsiA subfamily and is plasmid encoded in A. marina, and $\mathrm{CBPIa} / \mathrm{d}$.

As expected, the genomic data confirmed the absence of phycoerythrin genes. However, we were surprised to find not a single copy of a phycocyaninrelated gene. In $A$. marina MBIC11017, the genes for the phycocyanin $\alpha-(c p c A)$ and $\alpha$-subunits $(c p c B)$ as well as the gene for the phycobilisome rod-core linker polypeptide $(c p c G)$ are located in a single cluster on plasmid pREB3. None of these genes is present in Acaryochloris sp. HICR111A, despite the fact that other parts of plasmid pREB3 are well conserved. In contrast, all allophycocyanin-related genes are present. We even found an additional fourth copy of the allophycocyanin $\alpha$-subunit gene $(a p c A)$. The phylogenetic tree in Figure 12 visualizes their relationship to each other and to other phycobiliproteins of cyanobacteria and red algae. The fourth copy of ApcA is distinct from the other three. Instead of grouping with homologous ApcA from Acarychloris marina, it seems to share more sequence similarity with Cyanothece and Crocosphaera ApcA. With all subunits present we conclude that allophycocyanin is present in the novel strain. As there is no evidence for phycocyanin, the photosynthesis apparatus is clearly distinct between the new Acaryochloris isolate HICR111A and A. marina MBIC11017.

\section{Conclusions}

We isolated a novel cyanobacterial strain that groups within the genus Acaryochloris. It uses Chl $d$ as a main photopigment and is similar to A. marina in cell size and shape. Electron micrographs show that the novel strain Acaryochloris sp. HICR111A grows in cell aggregates that are surrounded by an extracellular matrix. This property has been observed for other isolates and we suggest that aggregated growth might be common for the family Acaryochloris, provided it is not influenced or triggered by habitat conditions or symbiotic factors. Allophycocyanincoding genes were observed in HICR111A, but phycocyanin genes were not. In fact, $A$. marina MBIC11017 seems to be the only strain that expresses phycobiliproteins on a physiologically relevant level (Chan et al., 2007). So far, A. marina MBIC11017 is the only member of the genus with a fully annotated genome. In A. marina, all phycocyanin-related genes are located on plasmid pREB3 and seem to be absent in Acaryochloris sp. HICR111A with strong support from our genomic data set. One factor that may contribute to genetic diversity within the group is the high number of transposable elements in Acaryochloris. Phylogenetic data support the idea of high diversity; however, it has to be pointed out that the Acaryochloris clade needs to be sampled and cultured more intensively on a global scale. A major consideration should be whether new species should be defined 


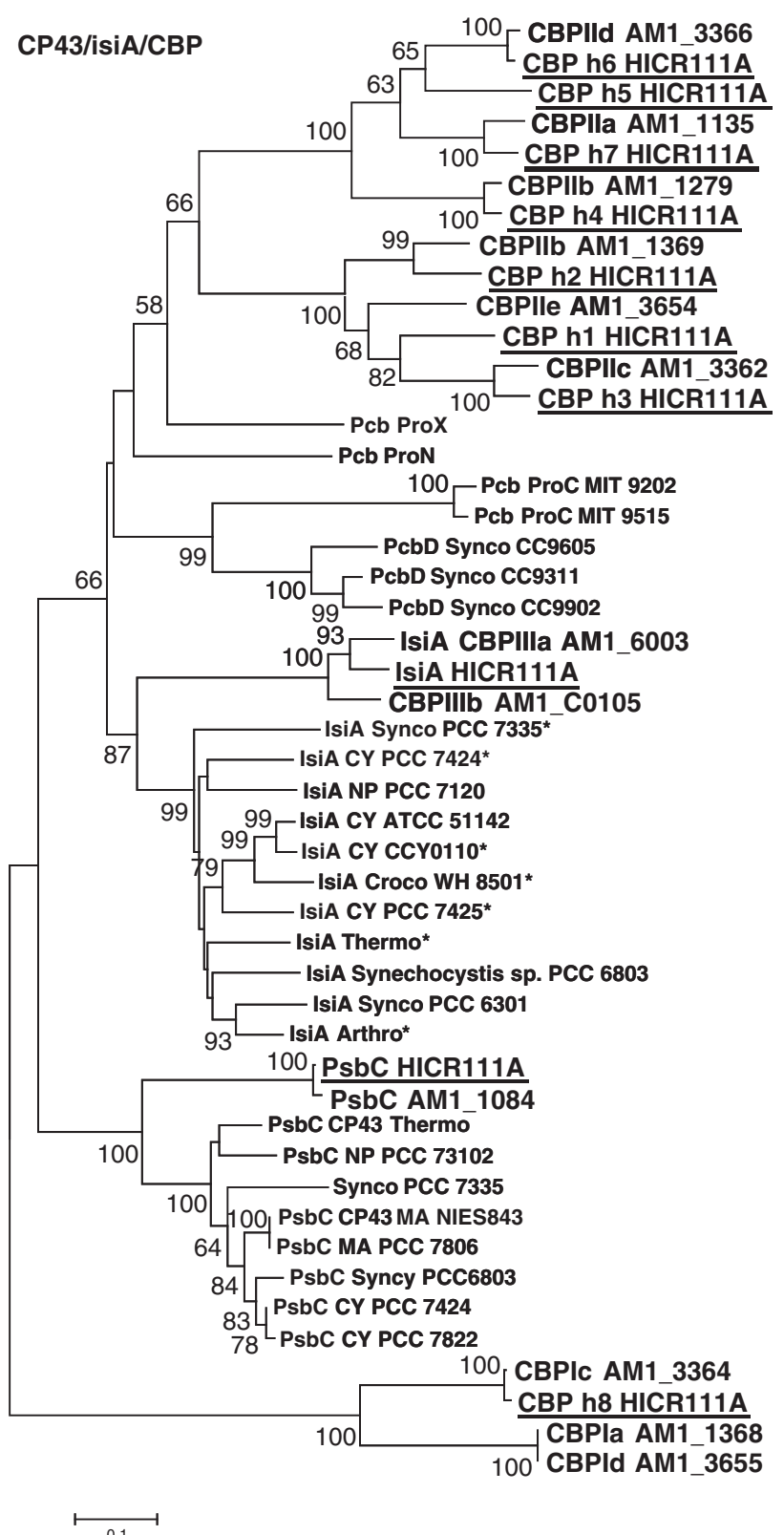

Figure 11 Phylogenetic tree of chlorophyll-binding proteins belonging to the CP43 superfamily, encoded by $p s b$, isiA, pcb and their homologues in Acaryochloris and other cyanobacteria. Protein IDs are given for the $A$. marina sequences, and the positions of Acaryochloris sp. HICR111A proteins are underlined (and see Table 1 for additional details). The percentage of replicate trees in which the associated taxa clustered together in the bootstrap test is shown next to the branches when $>50$. Other taxa: Prochlorothrix hollandica (ProX), Prochloron didemni (ProN), Prochlorococcus marinus (ProC), Synechococcus sp. (Synco), Cyanothece sp. (CY), Nostoc punctiforme (NP), Crocosphaera watsonii (Croco), Thermosynechococcus elongatus BP-1 (Thermo), Arthrospira maxima CS-328 (Arthro), and Microcystis aeruginosa (MA). Asterisks indicate annotation inferred by sequence alignment.

within the clade, as habitat, morphology and photochemical properties seem to be diverse. The characterization of such microbes will facilitate the

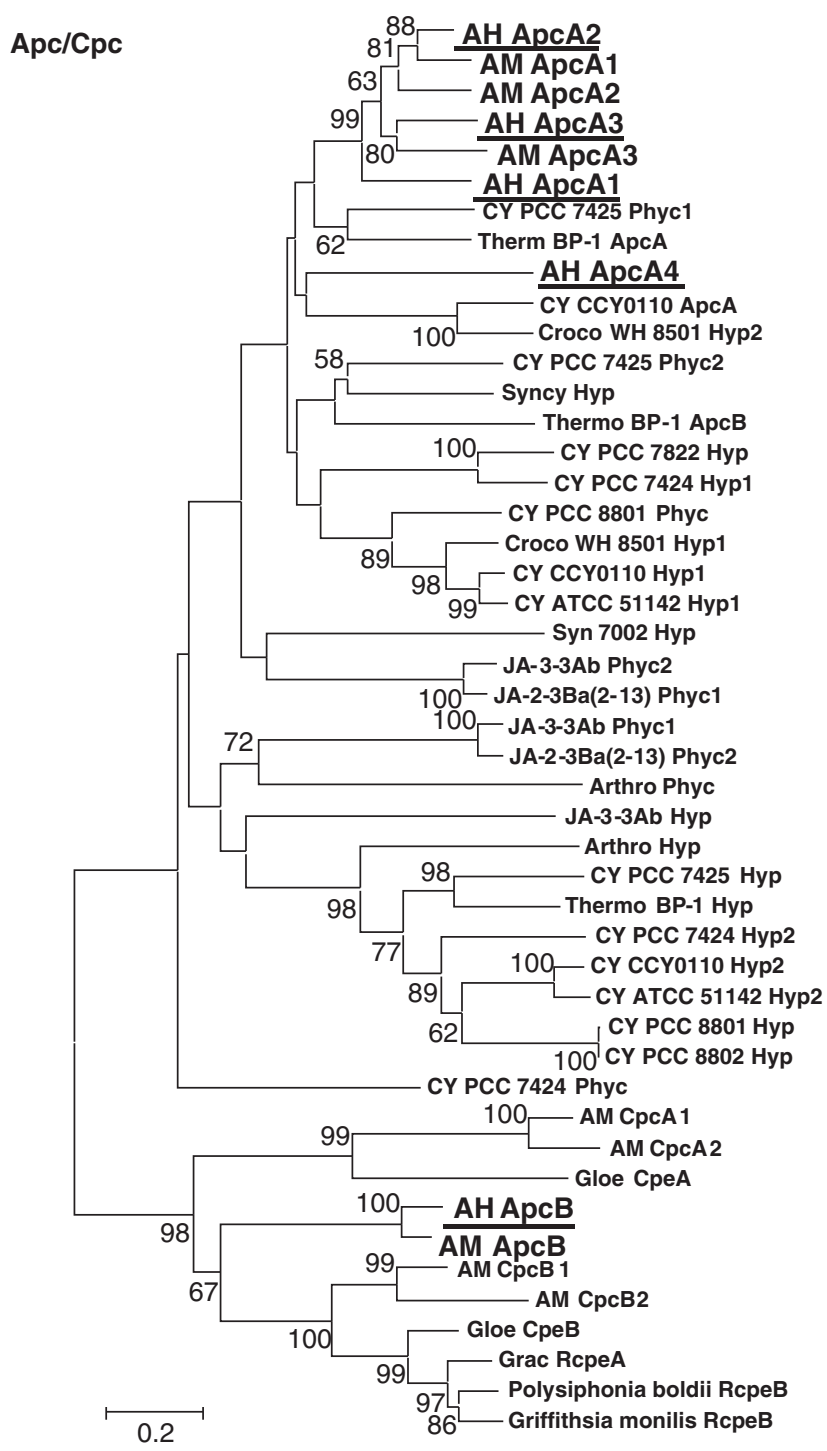

Figure 12 Phylogenetic tree showing the relationships among allophycocyanin subunits (ApcA or ApcB) and selected other phycobiliproteins in Acaryochloris, other cyanobacteria and red algae. The positions of Acaryochloris sp. HICR111A proteins are underlined. The percentage of replicate trees in which the associated taxa clustered together in the bootstrap test (1000 replicates) is shown next to the branches when $\geqslant 50$. If present, the original annotation is given. Abbreviations: $\mathrm{Cpc}$, cyanobacterial phycocyanobilin; Cpe, cyanobacterial phycoerythrin; Hyp, hypothetical protein; Phyc, phycobiliprotein; Rcpe, red algal phycoerythrin. Taxon abbreviations: Acaryochloris marina (AM), Acaryochloris sp. HICR111A (AH), Synechococcus sp. (Syn), Synechococcus sp. JA-2-3B'a(2-13) (JA-2-3Ba(2-13)), Synechococcus sp. JA-3-3Ab (JA-3-3Ab), Gloeobacter violaceus PCC 7421 (Gloe), Gracilaria tenuistipitata var. liui (Grac) or as in Figure 10.

understanding of life in an ecological niche depleted in visible light but abundant in infrared light. The Acaryochloris sp. HICR111A described in this study has been deposited in the Roscoff Culture Collection from where it is publicly available under the accession number RCC1983. 


\section{Acknowledgements}

WRH, RM, AWDL and MC thank the German Academic Exchange Service (DAAD)-Group of Eight funding scheme for supporting international cooperation. MC holds an Australian Research Council QE II Fellowship.

\section{References}

Akimoto S, Murakami A, Yokono M, Koyama K, Tsuchiya T, Miyashita $\mathrm{H}$ et al. (2006). Fluorescence properties of the chlorophyll $d$-dominated cyanobacterium Acaryochloris sp. strain Awaji. J Photochem Photobiol A Chem 178: 122-129.

Aziz RK, Bartels D, Best AA, DeJongh M, Disz T, Edwards RA et al. (2008). The RAST server: rapid annotations using subsystems technology. BMC Genomics 9: 75.

Chan YW, Nenninger A, Clokie SJ, Mann NH, Scanlan DJ, Whitworth AL et al. (2007). Pigment composition and adaptation in free-living and symbiotic strains of Acaryochloris marina. FEMS Microbiol Ecol 61: 65-73.

Chen M, Floetenmeyer M, Bibby TS. (2009). Supramolecular organization of phycobiliproteins in the chlorophyll $d$-containing cyanobacterium Acaryochloris marina. FEBS Lett 583: 2535-2539.

Chen M, Hiller RG, Howe CJ, Larkum AW. (2005). Unique origin and lateral transfer of prokaryotic chlorophyll- $b$ and chlorophyll- $d$ light-harvesting systems. Mol Biol Evol 22: 21-28.

Chen M, Quinnell RG, Larkum AW. (2002). The major light-harvesting pigment protein of Acaryochloris marina. FEBS Lett 514: 149-152.

Chen M, Zhang Y, Blankenship RE. (2008). Nomenclature for membrane-bound light-harvesting complexes of cyanobacteria. Photosynth Res 95: 147-154.

Cho JC, Giovannoni SJ. (2003). Parvularcula bermudensis gen. nov., sp. nov., a marine bacterium that forms a deep branch in the $\alpha$-Proteobacteria. Internat J Syst Evol Microbiol 53: 1031-1036.

de los Rios A, Grube M, Sancho LG, Ascaso C. (2007). Ultrastructural and genetic characteristics of endolithic cyanobacterial biofilms colonizing Antarctic granite rocks. FEMS Microbiol Ecol 59: 386-395.

Dufresne A, Ostrowski M, Scanlan DJ, Garczarek L, Mazard S, Palenik BP et al. (2008). Unraveling the genomic mosaic of a ubiquitous genus of marine cyanobacteria. Genome Biol 9: R90.

Duxbury Z, Schliep M, Ritchie RJ, Larkum AW, Chen M. (2009). Chromatic photoacclimation extends utilisable photosynthetically active radiation in the chlorophyll $d$-containing cyanobacterium, Acaryochloris marina. Photosynth Res 101: 69-75.

Fiedler G, Arnold M, Hannus S, Maldener I. (1998). The DevBCA exporter is essential for envelope formation in heterocysts of the cyanobacterium Anabaena sp. strain PCC 7120. Mol Microbiol 27: 1193-1202.

Finsinger K, Scholz I, Serrano A, Morales S, Uribe-Lorio L, Mora $\mathrm{M}$ et al. (2008). Characterization of true-branching cyanobacteria from geothermal sites and hot springs of Costa Rica. Environ Microbiol 10: 460-473.

Gloag RS, Ritchie RJ, Chen M, Larkum AW, Quinnell RG. (2007). Chromatic photoacclimation, photosynthetic electron transport and oxygen evolution in the chlorophyll $d$-containing oxyphotobacterium Acaryochloris marina. Biochim Biophys Acta 1767: 127-135.
Goh F, Allen MA, Leuko S, Kawaguchi T, Decho AW, Burns BP et al. (2009). Determining the specific microbial populations and their spatial distribution within the stromatolite ecosystem of Shark Bay. ISME J 3: 383-396.

$\mathrm{Hu}$ Q, Marquardt J, Iwasaki I, Miyashita H, Kurano N, Morschel E et al. (1999). Molecular structure, localization and function of biliproteins in the chlorophyll a/d containing oxygenic photosynthetic prokaryote Acaryochloris marina. Biochim Biophys Acta 1412: 250-261.

Huelsenbeck JP, Ronquist F. (2001). MRBAYES: Bayesian inference of phylogenetic trees. Bioinformatics 17: $754-755$.

Jeffrey SW, Vesk M. (1997). Introduction to marine phytoplankton and their pigment signatures. In: Jeffrey SW, Mantoura RFC, Wright SW (eds). Phytoplankton Pigments in Oceanography. UNESCO: Paris. pp 37-84.

Kashiyama Y, Miyashita H, Ohkubo S, Ogawa NO, Chikaraishi Y, Takano Y et al. (2008). Evidence of global chlorophyll $d$. Science 321: 658.

Kettler GC, Martiny AC, Huang K, Zucker J, Coleman ML, Rodrigue S et al. (2007). Patterns and implications of gene gain and loss in the evolution of Prochlorococcus. PLoS Genet 3: e231.

Kühl M, Chen M, Ralph PJ, Schreiber U, Larkum AW. (2005). Ecology: a niche for cyanobacteria containing chlorophyll $d$. Nature 433: 820.

LaRoche J, van der Staay GW, Partensky F, Ducret A, Aebersold R, Li R et al. (1996). Independent evolution of the prochlorophyte and green plant chlorophyll $a / b$ light-harvesting proteins. Proc Nat Acad Sci USA 93: 15244-15248.

Lokstein H, Steglich C, Hess WR. (1999). Light-harvesting antenna function of phycoerythrin in Prochlorococcus marinus. Biochim Biophys Acta 1410: 97-98.

Manning WM, Strain HH. (1943). Chlorophyll $d$ : a green pigment in red algae. J Biol Chem 151: 1-19.

Marquardt J, Senger H, Miyashita H, Miyachi S, Morschel E. (1997). Isolation and characterization of biliprotein aggregates from Acaryochloris marina, a Prochloronlike prokaryote containing mainly chlorophyll $d$. FEBS Lett 410: 428-432.

McNamara CJ, Perry IV TD, Bearce KA, Hernandez-Duque G, Mitchell R. (2006). Epilithic and endolithic bacterial communities in limestone from a Maya archaeological site. Microb Ecol 51: 51-64.

Miller SR, Augustine S, Olson TL, Blankenship RE, Selker J, Wood AM. (2005). Discovery of a free-living chlorophyll $d$-producing cyanobacterium with a hybrid proteobacterial/cyanobacterial small-subunit rRNA gene. Proc Natl Acad Sci USA 102: 850-855.

Miyashita H, Ikemoto H, Kurano N, Adachi K, Chihara M, Miyachi S. (1996). Chlorophyll $d$ as a major pigment. Nature 383: 402.

Miyashita H, Ikemoto H, Kurano N, Miyachi S, Chihara M. (2003). Acaryochloris marina gen. et sp. nov. (cyanobacteria), an oxygenic photosynthetic prokaryote containing Chl $d$ as a major pigment. J Phycol 39: 1247-1253.

Murakami A, Miyashita H, Iseki M, Adachi K, Mimuro M. (2004). Chlorophyll $d$ in an epiphytic cyanobacterium of red algae. Science 303: 1633.

Reynolds ES. (1963). The use of lead citrate at high $\mathrm{pH}$ as an electron-opaque stain in electron microscopy. J Cell Biol 17: 208-212. 
Ritchie RJ. (2006). Consistent sets of spectrophotometric chlorophyll equations for acetone, methanol and ethanol solvents. Photosynth Res 89: 27-41.

Ritchie RJ. (2008). Fitting light saturation curves measured using modulated fluorometry. Photosynth Res 96: 201-215.

Rocap G, Larimer FW, Lamerdin J, Malfatti S, Chain P, Ahlgren NA et al. (2003). Genome divergence in two Prochlorococcus ecotypes reflects oceanic niche differentiation. Nature 424: 1042-1047.

Ronquist F, Huelsenbeck JP. (2003). MrBayes 3: Bayesian phylogenetic inference under mixed models. Bioinformatics 19: 1572-1574.

Saitou N, Nei M. (1987). The neighbor-joining method: a new method for reconstructing phylogenetic trees. Mol Biol Evol 4: 406-425.

Scanlan DJ, Ostrowski M, Mazard S, Dufresne A, Garczarek L, Hess WR et al. (2009). Ecological genomics of marine picocyanobacteria. Microbiol Mol Biol Rev 73: 249-299.
Steglich C, Mullineaux CW, Teuchner K, Hess WR, Lokstein H. (2003). Photophysical properties of Prochlorococcus marinus SS120 divinyl chlorophylls and phycoerythrin in vitro and in vivo. FEBS Lett 553: 79-84.

Swingley WD, Chen M, Cheung PC, Conrad AL, Dejesa LC, Hao J et al. (2008). Niche adaptation and genome expansion in the chlorophyll $d$-producing cyanobacterium Acaryochloris marina. Proc Natl Acad Sci USA 105: 2005-2010.

Tamura K, Dudley J, Nei M, Kumar S. (2007). MEGA4: molecular evolutionary genetics analysis (MEGA) software version 4.0. Mol Biol Evol 24: 1596-1599.

Wyman M, Gregory RPF, Carr NG. (1985). Novel role for phycoerythrin in a marine cyanobacterium, Synechococcus strain DC2. Science 230: 818-820.

Zerbino DR, Birney E. (2008). Velvet: algorithms for de novo short read assembly using de Bruijn graphs. Genome Res 18: 821-829. 